\title{
O INCONSCIENTE E O SER DA ANÁLISE
}

\author{
LUDMILA KLOCZAK 1
}

KLOCZAK, L. O inconsciente e o ser da análise. Semina: Ci., Soc./Hum., Londrina, v. 13, n. 3, p. $208-211$, set, 1992.

RESUMO: A autora procura explicar o mecanismo de funcionamento dos processos inconscientes, a origem do inconsciente e sua relação com a consciéncia e os processos secundários correlacionando estes aspectos com a funçắo e os limites da análise.

PALAVRAS-CHAVE: Processos primários - processos secundários; Principio do prazer - principio da realidade; Origem do inconsciente; Ser da análise.

"uma parte de mim é multidăo; outra parte estranheza e solidão..."

(Ferreira Gullar)

Entre os fundamentos na constituição da teoria psicanalitica destaca-se a conceituação e a distinçảo entre os dois modos de funcionamento do aparelho psiquico, o processo primário e o processo secundário, cuja compreensāo remete e envolve os dois modos de circulaçăo da energia pslquica, a energia livre e a energia ligada, bem como, a oposição entre o princlpio do prazer e o princlpio da realidade.

Os processos primários surgem das perturbaçōes provocadas pelas necessidades básicas internas. Naturalmente, nảo há um estado original de repouso a partir do qual aparecem as sensações de prazer-desprazer. Mas a sua concepçăo, mesmo ficcional, é útil para compreender o funcionamento da vida mental e, quiçá, a gênese do inconsciente.

O propósito dominante dos processos primários e o de alcançar o prazer e evitar o desprazer, objetivo este que o psiquismo pretende atingir atravês de alucinaçōes; tal como se observa nos pensamentos oniricos.

A impossibilidade de satisfação por esta via e a frustraçäo forçam o aparelho pslquico a considerar as circunstâncias reais no mundo externo e a constituir o prínclpio da realidade através dos processos pslquicos secundârios.

Enquanto os processos primários correspondem a uma forma de energia livre, que tende para a descarga de forma mais direta possivel, os processos secundários expressam-se através da energia ligada cuja descarga é retardada ou controlada (GARCIA-ROZA, 1988).
A passagem do princlpio de prazer para o princlpio de realidade deve-se essencialmente à repressão primária que regula a utilização dos mecanismos alucinatórios. Isto porque, num primeiro momento, o psiquismo trata os est/mulos desagradáveis internos como se fossem externos, empurrando-os para o mundo externo.

Com a introdução do princlpio da realidade entra em açāo a consciência, a qual, alếm das qualidades de prazer e desprazer, passa a incluir qualidades sensoriais e perceptivo-motoras na avaliaçăo da realidade.

Para tanto, desenvolvem-se funçōes da consciência, tais como, a atençăo, a memória, o julgamento. Inclusive, a descarga motora que, até entāo, servira para aliviar o aparelho mental do acúmulo de estímulos, passa a desempenhar um papel ativo sobre a realidade.

Isto só é possivel através do processo do pensar, que permite ao aparelho mental tolerar as tensōes produzidas pelos est/mulos, deslocando pequenas quantidades de catexias junto com menor dispêndio de energia.

Freud assinala em um artigo de 1911 que o pensar originalmente era inconsciente, nảo ultrapassando simples apresentaçōes ideativas associadas a relaçōes entre impressōes de objetoș, só vindo a adquirir um estatuto epistêmico ao ligar-se a residuos verbais (FREUD, 1969).

Entretanto, nem toda a atividade do pensamento foi colocada a serviço do princlpio da realidade, assim como as fontes de prazer nāo foram destruldas. Ao contrário, a tendéncia do aparelho mental em poupar energia não abdicando das fontes primárias de prazer, levou à separação de uma parte da atividade de pensamento e a sua subordinaçăo somente ao princlpio do prazer. Esta atividade é o fantasiar que pode ser observada nas brincadeiras infantis e, posteriormente, nos devaneios.

1 - Departamento de Fundamentos de Psicologia e Psicanálise/Centro de Ciências Biológicas, Universidade Estadual de Londrina, Caixa Postal 6001, CEP 86051-970, Londrina - Paraná - Brasil. 
O que se pode depreender das fantasias e dos fenómenos lacunares $\hat{e}$ o desprezo pelo teste da realidade, tfpico dos processos inconscientes. Eles equiparam a realidade interna com a externa e o desejo com a sua realização.

Estes atos pslquicos com o seu modo peculiar de funcionamento fazem parte de uma estrutura, de um sistema de leis multideterminado, com uma sintaxe propría e que está a serviço da pulsão. Este sistema é o inconsciente, pedra de toque da psicanálise, cuja existência $e$ vias de acesso foram determinadas por Freud.

Dentre as caracteristicas do inconsciente, reconhecemos as representaçōes pulsionais que procuram descarregar sua catexia, ou seja, impulsos carregados de desejo, que buscam satisfação.

Como a finalidade do inconsciente afirmar o desejo, este busca caminho ao consciente até pela coexistência e combinaçăo de representações contraditórias. Nảo há negação e incompatibilidade entre as mesmas.

0 inconsciente 6 regido pelos processos primários, através de deslocamento e condensação, e atende ao princlpio do prazer. Sua energia é livre e vive deslizando de uma representação para outra, procurando descarga rápida.

Esse deslizamento contInuo confere um caráter absurdo às representaçôes quando assomam à consciência. É o que se observa nos sonhos, nos sintomas.

GARCIA-ROZA (1988) observa que o movimento da energia pulsional é contínuo e ininterrupto, conferindo às representaçōes atemporalidade: nem sāo ordenadas no tempo, nem sofrem desgaste do tempo.

Temos, entāo, que o aparelho psiquico funciona de acordo com dois sistemas, o inconsciente e o pré-consciente-consciente, os quais atendem a dimensōes diferentes da açäo psiquica.

Sem dúvida, os produtos da atividade inconsciente podem penetrar na consciência, e o fazem por vias indiretas, mas a sua manifestaçāo consciente sofre os efeitos da resistência. Este fenómeno denota que a exclusão da idéia inconsciente obtida através do concurso de forças vivas e intensas, que se opōem à sua recepçāo.

Ao definir as caracteristicas do inconsciente em um artigo de 1915, Freud observa que a inconsciência é uma fase regular e inevitável nos processos que constituem nosse atividade psfquica. Todo ato psíquico começa como um ato inconsciente e pode permanecer assim ou evoluir para a consciência, segundo encontra resistência ou năo. A distinçāo entre atividade pré-consciente $e$ inconsciente não é primária, mas estabelece-se após a repressäo ter surgido. Somente al a diferença entre idéias prt-conscientes, que podem aparecer na consciência e reaparecer a qualquer momento, e idéias inconsćientes que nảo podem fazê-lo, adquire um valor tanto teórico quanto prático (FREUD, 1974).

LACAN (1983) considera que a origem do inconsciente situa-se na entrada do sujeito no simbólico. A pulslo ilimitada confronta-se com a perda originária representada pela primeira experiência de satisfaçāo ou gozo, que é traumática pelo que contém de inatinglvel e que foge a significação, pois é vivida ao nivel corporal, sem inscriçäo pslquica.

Este momento junta-se imediata e simultaneamente ao segundo momento que é o da significação. Ao recobrir esta satisfaçāo primária, o simbólico possibilita a inscriçāo do sujeito no mundo das representaçōes. Determina-se o sujeito, mas perde-se o prazer originário não simbolizável, marca da incompletude do ser humano.

O vazio primário vai sendo ocupado por diversos objetos, permutáveis entre si, cuja catexia é proporcional à possibilidade de satisfação pulsional.

Inicialmente, o que predomina a necessidade de auto-preservação. Paralelamente à satisfação de uma necessidade básica pela amamentaçāo produz-se prazer ao sugar. Este e o ponto de emergência da pulsão. A libido es contida nos limites das zonas erógenas.

Neste sentido, os objetos que satisfazem à pulsão sāo introjetados pelo ego e os que produzem desprazer são expelidos. A passagem do interno para o externo se faz de modo fantasmático, ao nlvel do imaginário.

A natureza dos elementos que fazem parte do imaginário é a experiência corporal de uma diferença erógena. Corresponde a uma experiência sensorial da diferença, à discriminação, à percepção de uma diferença e à experiência dessa distinção diferencial enquanto tal. Os primeiros representantes da pulsão seriam, então, as impressōes táteis, olfativas e cinestésicas da diferença e as suas oposiçōes.

O recalque originário e a emergência do inconsciente ocorreriam quando fosse negado acesso ao consciente destes representantes da pulsão, estabelecendo-se uma fixação do representante à pulsão e a busca de recursos simbólicos, ou seja, da linguagem para ultrapassar o sujeito consciente e constituir-se o Outro do desejo (FREUD, 1972; GARCIA-ROZA, 1988).

Após estas consideraçōes iniciais que definem um quadro bastante resumido da origem do inconsciente, tentaremos abordar questōes referentes à representação e sua origem no contexto do psiquismo.

A análise teórica do inconsciente sofre as influências das limitaçōes próprias de uma lógica identitária, que tem sido o modo de pensar norteador do vasto campo do saber humano.

CASTORIADIS (1982) revela a insuficiéncia deste modo de pensar, pois não abarca todos os fenómenos conhecidos, seja na física, seja no campo das ciências humanas.

Assim, pensar o inconsciente implica em considerar a emergéncia de uma alteridade, de um novo inesperado, indefinido e indefinivel a nāo ser parcialmente. Não se alcança o inconsciente através da relação de causalidade. Esta representa a negaçāo da alterídade e a afirmaçāo da identidade: "identidade na repetição das mesmas causas produzindo os mesmos efeitos, identidade última da causa e do efeito, posto que cada um pertence necessariamente ao outro ou os dois a um mesmo" (CASTORIADIS, 1982, p. 207). 
A partir da lógica identitária os acontecimentos contêm significaçōes racionais que podem e devem ser produzidas umas a partir de outras.

O novo é construldo atravếs de operaçōes de escoina, distinção, definição, determinação, isto ê, tudo é dedutivel, produzlvel a partir do que existe.

Quando se trata do ser do inconsciente, sua existência e modo de ser escapam desta lógica.

Neste sentido, o autor enfatiza a importância da grande descoberta freudiana acerca do inconsciente.

A afirmativa de que o inconsciente ignora o tempo e a contradição expōe as deficiências da lógica tradicional. Senão, vejamos. $O$ inconsciente constitui um "lugar" onde o tempo identitário determinado por e determinando uma sucessão ordenada de eventos nāo existe, onde os contraditórios não se excluem mutuamente, onde nem se cogita de contraditórios e nem é verdadeiramente um lugar, jấ que o lugar implica a ordem e a distinção (CASTORIADIS, 1982).

Não se trata apenas do avanço do conhecimento que exige modificaçōes teóricas, mas da própria natureza do objeto que nāo se deixa categorizar, organizar. Cedo ou tarde, toda conjuntura teórica mostra-se parcial, lacunar, fragmentária, insuficiente. Soluçōes teóricas utilizadas engendram novos enigmas, cujas relaçöes com as anteriores permanecem intratáveis e inapreensiveis pela lógica identitária.

A representação material essencial do inconsciente, escapa aos esquemas lógicos mais elementares, não se submete às exigências da determinidade.

Somos quase que irresistivelmente atraldos pela tentação de submeter o inconsciente ou a um modelo mecanicista ou a uma estrutura lingulstica. Assim como utilizamo-nos da visão adulta para compreender as experiências infantis, imputando às crianças vivências que nāo sâo suas, deformando-as, assim também traduzimos numa linguagem logicista o modelo de ser e a organização do inconsciente (CASTORIADIS, 1982).

Não seria uma manifestação do inconsciente esta tendência humana de estabelecer determinismo naquilo que näo se determina?

Por exemplo, a análise dos sonhos nos remete à representaçăo inconsciente tal como ela é, caracterizada pela fusāo, pela indistinçăo. Năo se trata de figuras separadas, claras e distintas que estariam embaralhadas, mas sim do ser da psiquê que é gênese de representaçōes, as quais em número infimo e de cunho arcaico eram para a psiquê o "mundo" do qual o longo trabalho da formaçāo do indivlduo as separou para fins da existência em vigilia, e que nos remetem ao enlgma de um representar-representaçāo originário.

A representação, que aliás nāo pode ser separada da intençăo inconsciente e do afeto, não é analisável. Toda decomposiçāo em elementos é provisória e artificial.

A representação 6 indefinida e nāo tem fronteiras. A todo momento revela-se a sua năo-pertinência a qualquer relaçāo determinada. Mesmo a livre-associaçăo que năo 6 livre e nem nảo-livre, um desvendar parcial de aspectos de um co-pertencer, que jamais saberemos dizer se já preexistia à sua formulação ou é criado por ela. A associaçăo age como um fio condutor entre tramas de uma malha que, ora são pontos, ora sāo linhas, e que sempre deixam dúvidas se estão sendo revelados ou criados e transformados na cadeia associativa. $A$ relação entre os termos é constantemente redefinida, ora aproximando-os, ora separando-os indefinidamente ICASTORIADIS, 1982).

Esta questão remete-nos ao ser do analista que tem por função interpretar aquilo que nāo se deixa capturar. Mas, então, o que faz o analista? Fala da representaçāo. $E$ o faz utilizando-se de fragmentos que são fixados, que representam o papel de pontos de referéncia traduzidos em palavras, de maneira que se possa, por aproximação, saber "de que se fala". Mas não podemos reduzir estes fragmentos fixados pela linguagem a operaçōes conjuntistas e identitárias e, menos ainda, a construçōes precisas e exatas.

Neste aspecto, a interpretaçāo, ao estabelecer uma lógica e uma ordem nas representaçōes inconscientes e determinar um sentido, não suprime o ser da representação. Isto é, o modo de ser, o nivel de ser e o ser-assim do delfrio ou da alucinaçăo ou do conteưdo onirico não são anulados pela constatação de que o seu conteưdo é interpretável, do mesmo modo que o ser-cor da cor năo é anulado pelas equaçōes da flsica. Al está o sutil desvio da Iógica identitária: acreditar que o ser é capturado atravếs da interpretaçăo.

A verdadeira interpretaçăo ocorre num contexto polltico-poético singular, o da análise. Os sentidos que se encontram para as representaçōes só valem no contexto da análise. Escapam da lógica identitária, pois não atendem aos critérios de generalização, verificaçāo por repetição. Isto nāo quer dizer que a interpretaçāo ế arbitrária, possa ser qualquer coisa. A significaçăo pode ser permanentemente retomada e só existe para o sujeito "analisado", sujeito enigmático por excelência, desconhecido nem o paciente tal como é, nem o paciente tal como deveria ser, de acordo com uma norma fixada a priori, mas o paciente tal como se faz e se fará no e pelo processo analítico (CASTORIADIS, 1982).

Por isso a análise é interminável. Cada vez que se estabelece uma equivalência de sentido, dissolve-se a ligaçăo de representaçăo com a palavra e aquela assoma em outro lugar, revelando outras rupturas e descontinuidades.

Freud em uma obra que se tornou um dos pilares da teoria psicanalitica, datada de 1900 , compreendeu a dimensão da ação inconsciente quando, ao tratar dos sonhos, afirmou que "existe pelo menos um ponto em todo o sonho no qual ele é insondável - um umbigo, por assim dizer, que é seu ponto de contato com o desconhecido" (FREUD, 1972b, p. 560).

Retomando as deduçōes de Freud a respeito do que está além do sonho, alếm do esquecimento, alếm do sintoma, Lacan assinala que "aquilo de que se trata o tempo todo de um desejo. Esse desejo corre como um 
anel que vemos desaparecer e reaparecer num jogo de passa-passa" (LACAN, 1983, p. 58)

É da natureza do inconsciente não ser subjugado numa totalidade. Mesmo num sonho mais completamente interpretado, encontrar-se-â uma passagem que permanecerá obscura. É como se houvesse um enovelamento de pensamentos oníricos que não se dá a conhecer e que, ademais, näo contribui em nada para o entendimento do conteúdo do sonho.

Os pensamentos onfricos a que se chega pela interpretaçăo não podem, pela natureza da pulsão, possuir qualquer término definido. Tendem a ramificar-se em todas as direçóes dentro da intrincada rede de nosso mundo mental, à procura de novos pontos de emergência. E é destes pontos que o "desejo onírico se desenvolve, como um cogumelo de seu micélio" (FREUD, 1972b, p. 560).

O analista se depara o tempo todo, seja na sua prática analftica, seja na sua análise pessoal, seja na análise da prática, com este saber que desliza, que a cada vez é outra coisa, o desconhecido que fala dentro do sujeito através de lacunas, de rupturas, de sintomas.

Não se pode ter a pretensão de chegar ao ámago, porque aquilo que parecia ser o cerne se desfaz e se transforma em outra coisa.

A consciência de que está investido de um suposto saber que nada sabe sobre o sujeito do inconsciente, leva o analista a destituir -se de uma posição narcisista e verificar que não resolve os problemas do ser humano. No máximo, e esta é sua tarefa, pode ampliar o campo da consciéncia ou da enunciação de modo a que o sujeito passe a determinar a sua conduta.

KLOCZAK, L. The unconscious and the being of analysis. Semina: Ci. Soc./Hum., Londrina, v. 13, n. 3, p. 208-211, Sept 1992

ABSTRACT: The author tries to explain the mechanism of the unconscious functioning processes, the origin of the unconscious and its relation with the consciousness and the secondary processes and its interrelation with the function and the limits of analysis.

KEY-WORDS: Primary processes - Secondary processes; Pleasure principle - Reality principle; Origin of the unconscious; The being of analysis.

\section{REFERÊNCIAS BIBLIOGRAFICAS}

CASTORiads, C. A instituiça imaginária da sociodade. S4o Paulo: Paz e Terra, 1992.

FrEUD, 5. Obras psicologicas completas de Sigmund Froud. Rio de denitro: imago, 1859. v. 12, p. 270-205: Formulagbes sobre os dole princlpios do funclonmmento montel (1911)

—. Rlo de Janelro: Inago, 1969. v. 12, p. 328-334: Uma nota sobre o Inconsclente na pelcantlbe (1912).

Flo de Janeiro: Imago, 1974. v. 14, p. 213-217:0 inconeclente (1915).

\author{
- Rlo de Janelro: Imago, 1972a. v. 14: A Interpretaçto \\ dos eonhos (1900). \\ _- Rlo de Janelro: Imago, 1972b. v. 5: A Interpretackio \\ dos sonhos (1900). \\ GARCLAROZA, L.A. Froud e o inconsciente. 4. ed. Rlo de \\ Janeiro: Zahar, 1988. \\ LACAN, J. O seminario: escrttos benicos de Freud. 3. ed. Rlo \\ de Janeiro: Zahar, 1963.
}

Recebido para publicaçăo em 16/3/92 